2017-09-01

\title{
A person-centred approach to holistic assessment
}

\author{
MILLS, IAN
}

http://hdl.handle.net/10026.1/12258

$10.1308 / 205016817821931006$

Primary Dental Journal

Fgop

All content in PEARL is protected by copyright law. Author manuscripts are made available in accordance with publisher policies. Please cite only the published version using the details provided on the item record or document. In the absence of an open licence (e.g. Creative Commons), permissions for further reuse of content should be sought from the publisher or author. 


\section{A PERSON-CENTRED APPROACH TO HOLISTIC ASSESSMENT}

IAN JAMES MILLS

Prim Dent J. 2017;6(3):18-22

\section{ABSTRACT}

Holistic assessment is an important aspect of providing high quality care focused on meeting a patient's individual needs. A holistic assessment should take into consideration the overall health of the patient, including their physical, psychological, social and spiritual wellbeing. This paper aims to clarify the meaning of 'holistic' in relation to dentistry and describes how this relates to treating the person as a whole, rather than be aligned to any particular treatment philosophy.

The importance of a person-centred approach in undertaking a holistic assessment is highlighted. A brief overview of the relational aspects of personcentred care (PCC) is provided and it is suggested that four key dimensions of PCC should be considered as important factors in holistic assessment: connection, caring attitude, communication and control.

"The good physician treats the disease; the great physician treats the patient who has the disease." Sir William Osler

\section{KEY WORDS}

Holistic Assessment; Holistic Care; Person-centred Care; Patient-centred Care; Dentistry; General Dental Practice

\section{AUTHOR}

Ian James Mills BDS (Glasg.), MFDS RCPS (Glasg.), MJDF RCS (Eng.), Dip Imp Dent RCS (Eng.),FFGDP (UK), FDS RCPS (Glasg.), FHEA

Vice Dean, FGDP(UK); Partner at Torrington Dental Practice, Torrington, Devon; NIHR Academic Clinical Fellow in General Dental Practice and Honorary Lecturer, Plymouth University Peninsula Schools of Medicine \& Dentistry
P he focus of this themed edition of the Primary Dental Journal is 'Extended Integrated Care' and the aim of this article is to highlight the importance and relevance of a holistic approach in the management of dental patients. 'Holistic care' is a term which is frequently used to indicate a more comprehensive approach to patient care ${ }^{l}$ and is widely acknowledged as an important aspect of high quality care. ${ }^{2,3}$ According to Wade, holistic care can be defined as "an approach to analysing illness and providing healthcare that acknowledges and responds to all factors relevant to the health (or illness) of a person." 4 This indicates that health is dependent on many inter-related factors and reflects the importance of understanding the patient as a whole, rather than simply focusing on the disease or the illness.

In the 1950s, Michael Balint published his work 'The doctor, his patient and the illness ${ }^{5}$ which highlighted the importance of a holistic approach to patient care, with treatment focussed on the individual and not just centred on the disease. The author described the traditional biomedical approach as "illness-oriented medicine" and contrasted this to a "patient-centred" model which promoted a more holistic approach. This was subsequently referred to as the biopsychosocial model of care, ${ }^{6}$ where the overall wellbeing of the patient is taken into consideration to include physical, mental and spiritual health.

Balint's publication is widely regarded as a seminal text in the field of patientcentred care, although similar issues had been highlighted by Francis Peabody some 30 years earlier.' Peabody was a physician and leading medical educator at Harvard Medical School in the 1920s. He was influential in teaching medical students the importance of blending medical science and humanitarian care, and in 1926 gave a series of presentations entitled 'The Care of the Patient.' Within his presentations Peabody warned new graduates against focusing on the scientific basis of medicine while ignoring the 'art' of the patient relationship. ${ }^{7}$ The closing words in his final presentation are as apt today as they were over 90 years ago:" "One of the essential qualities of the clinician is interest in humanity, for the secret of the care of the patient is in caring for the patient."

Peabody's influence on future medical generations is revered within Harvard Medical School, but the relevance of holistic care was not a new concept in 1926, as the following quote attributed to Hippocrates indicates: "It is more important to know what sort of person has a disease than to know what sort of disease a person has."

This quote again highlights the importance of the person, rather than simply focusing on the disease. A particular condition, disease or illness can have vastly different consequences on separate individuals, and can even have a variable impact on the same 
individual depending on the person's circumstances at that time. A cracked cusp may be an inconvenience for some, but have significant functional and psychological impact for others. The ability of the individual to cope will be dependent on a number of factors, only some of which will be related to the nature and severity of the condition.

\section{A holistic approach acknowledges and addresses the physiological, psychological, sociological, developmental, spiritual and cultural needs of the patient. ${ }^{1}$ This has been recognised by the General Dental Council (GDC) and is included within Standards for the Dental Team: ${ }^{2}$ "A holistic approach means you must take account of patients' overall health, their psychological and social needs, their long term oral health needs and their desired outcomes."}

These are important factors and must be taken into consideration if we wish to provide holistic care, rather than simply deliver illness-oriented dentistry.

\section{'Holistic' in relation \\ to alternative or complimentary therapies}

The success of alternative or complimentary therapies is often attributed in part to the application of a more holistic approach to care. ${ }^{8}$ It is suggested that such practitioners may have greater focus on the overall wellbeing of the patient when compared to those practising conventional medicine. Non-allopathic therapies may form part of a holistic approach to care, but it would be inappropriate to assume that alternative medicine is somehow analogous to holistic care. Wade states that the word 'holistic' is increasingly used to promote certain specific types of treatment which often claim to be 'morally better' than conventional or allopathic medicine. ${ }^{4}$ The popularity of describing one's dental practice as 'holistic' can be easily demonstrated by a simple Google search of "holistic dentistry UK." Many of these dental practices highlight the importance of holistic dentistry with a significant number choosing to align holistic care with complimentary (alternative) therapy, replacement of amalgam restorations, elimination of harmful toxins and advice on the benefits of nutritional supplements.

In a series of articles on complimentary dentistry, Goldstein is highly critical of what he refers to as "unconventional dentistry" and the abundance of associated "pseudoscientific misinformation" promulgated on the Internet. ${ }^{9}$ Goldstein laments the lack of scientific rigour underpinning many unconventional treatments and suggests that dentists have "multiple and complex reasons for practising unconventional dentistry". ${ }^{10} \mathrm{He}$ reports that these reasons include "a genuine interest and belief in holistic health versus tooth-oriented practice" but also claims that this could be driven by less altruistic reasons such as "boredom with conventional dentistry, ego gratification and financial motivation." Ironically, the citation used to support this statement is the website 'Quackwatch'11 and not a peer reviewed article.

The merits, or otherwise, of complimentary therapies are beyond the scope of this article, but it is important to highlight the confusion which can exist around the term holistic care. Holistic care is about treating the patient as a person and giving consideration to the physical, psychological, social and spiritual well being of the individual. It is not about conventional or complimentary dentistry, it is about delivering whole patient care which is both person-centred and evidence based. ${ }^{12}$ This is equally appropriate and relevant to conventional medicine or dentistry as it is to the complementary therapies.

\section{Holistic dentistry}

As previously described, the biomedical model of care can no longer be considered appropriate, and physical health should not be managed without due consideration of the psychological and social needs of the patient. It is also important that oral health is not considered in isolation without giving due regard to the overall health of the patient. Many systemic conditions present with oral symptoms ${ }^{13}$ and the mouth is offen referred to as "the window on the rest of the body." ${ }^{14}$ There is now increasing evidence to suggest the relationship between oral and systemic disease is bidirectional, with recent scientific data reporting a significant association between periodontal disease and various systemic conditions, including diabetes and ischaemic heart disease. ${ }^{15-17}$

A recent article in the $B M$ highlighted the role of the dental profession in promoting better health, and opined the lack of integration within the wider healthcare. ${ }^{18}$ The authors reinforce the claim that it is "time to put the mouth back in the body" and that dentistry should be brought into the "medical mainstream." A more holistic approach to care is promoted, with particular reference to the impact of poor oral health on quality of life ${ }^{19}$ and the association of oral disease with various systemic conditions. ${ }^{20,21}$ The authors suggest greater co-operation across the healthcare professions in relation to "clinical practice, education, and research to promote an interprofessional wellness regime." This was based on shared common interests in conditions such as "diabetes and obesity, linked through sugar intake and (un)healthy eating." This appeal for a shift in attitude provides further acknowledgement of the need for a holistic approach in managing oral disease, and reflects the importance of oral health in the overall wellbeing of the patient.

Recent changes in undergraduate training have reflected the need to embrace a more holistic approach to patient care, with a paradigm shift from departmentalised, specialist led clinics to a more primary care based model. ${ }^{22}$ This provides an environment and attitude which "allows the students to focus on holistic patient care rather than a single discipline like a filling or an extraction." 22 This approach reflects the needs of healthcare in the 21 st Century and is clearly more representative of general dental practice, where the majority of students are likely to work following graduation.

\section{Holistic assessment}

The patient consultation, including assessment, is recognised as a critical step in providing effective patient care. 
Newsome et al ${ }^{23}$ describe this assessment stage in terms of the "collection and collation of information" and suggest that history-taking and clinical examination are two of the most important aspects in this process $^{23}$. The authors state that the main purpose of the history and examination is "to identify problems" and "establish their relative importance to the patient." ${ }^{23}$ The importance of a holistic perspective is highlighted and practitioners encouraged to view the patient as "a person with specific needs and not just a 'mouth to be fixed' or a 'case to be treated' in a predetermined manner." 23

Balint's description of "illness-oriented medicine" is equally appropriate to dentistry, where a strong focus on diagnosis and treatment is not uncommon, rather than addressing the circumstances which have led to the diseased state or the impact which this has on the individual. The NHS Five Year Forward View ${ }^{24}$ places significant emphasis on prevention, and this has been further recognised within the dental contract reform pilots in England. ${ }^{25}$

A feature of the pilots has been introduction of an oral health assessment $(\mathrm{OHA})$ as the entry point to a pathway of care. ${ }^{25}$ This demonstrates a significant shift from "a restorative approach to patient care to a preventive and long-term approach that is risk-based and meets the specific needs of individual patients. "26 Findings from the initial pilots indicated that patients and dentists appreciated this new way of working, and a potential improvement in oral health outcomes were also reported. ${ }^{27}$ The main challenge around the OHA was the increased time required and the impact this had on access. ${ }^{27,28}$ Refinements of the $\mathrm{OHA}$ are ongoing in an attempt to address some of these issues, although some commentators are sceptical of the likelihood of delivering access, prevention, and improvements in quality for the same (or less) funding. ${ }^{29,30}$

\section{The FGDP(UK) provides guidance} on Clinical Examination and RecordKeeping which includes details relating to history-taking and patent assessment. ${ }^{31}$ The importance of obtaining a thorough history is clearly stated, and this should include information on medical, personal, socio-behaviour and dental histories in addition to exploring attitude towards dental health. ${ }^{31}$ The Scottish Dental Clinical Effectiveness Programme (SDCEP) provides similar guidance and highlights the importance of "personalised care planning" 32 and recommends a flexible approach to ensure that a patient's needs are met. This level of flexibility and tailored care is a fundamental component of a person-centred approach and reinforces the benefits of undertaking a holistic assessment.

\section{A person-centred approach to holistic assessment}

The success of a holistic assessment is predicated on the ability to connect, communicate and understand the patient beyond the physical signs or symptoms. This involves considerable knowledge and skill, but "the importance of the attitudes underlying these skills should not be forgotten." 33 The acquisition and development of competent consultation skills are a fundamental component of any healthcare professional, and are viewed by some to be "just as important as keeping up-to-date with guidelines, new drugs, 'best practice', etc." ${ }^{134}$

The relevance of communication and interpersonal skills have been recognised as essential elements of dental training by the GDC, ${ }^{35}$ and the ability to communicate effectively is viewed as a fundamental requirement in taking a patient history. Kulich et a ${ }^{36}$ developed a model of a patient-centred consultation based on a series of interviews conducted with dentists working with anxious patients. The model was defined in terms of one overarching core principle - 'holistic perception and understanding of the patient' - and two underlying categories: 'the dentist's positive outlook on people' and 'the dentist's positive view of patient contact.'

The core category, 'holistic perception and understanding of the patient,' was

\section{REFERENCES}

1 Wallace S. The importance of holistic assessment - A nursing student perspective. Nuritinga 2013(12):24-30.

2 General Dental Council. Standards for the dental team. London: GDC; 2013

3 The Health Foundation. Personcentred care made simple. London: The Health Foundation; 2014

4 Wade DT, editor. Holistic Health Care: What Is It, and How Can We Achieve It? Nuffield Orthopaedic Centre's Annual General Meeting, Oxford, UK; 2009

5 Balint $M$. The doctor, his patient, and the illness. Lancet 1955;268(6866):683-8.

6 Mead N, Bower P. Patientempirical literature. Social Science \& Medicine 2000;51(7):1087TाO.

7 Peabody F. The Care of the Patient. Journal of the American Medical Association. 1927:88:877-82.

8 Henderson R. Holistic Medicine. Patient [serial on the Internet]. 2014: Available from: https:/ patient.info/doctor/holisticmedicine.

9 Goldstein BH. Unconventional dentistry: part I. Introduction. Journal of the Canadian Dental Association 2000;66(6):323-6.

10 Goldstein BH. Unconventional dentistry: Part II. Practitioners and patients. Journal of the Canadian Dental Association.
2000;66(7):381-3.

11 Quackwatch. 2017; Available at: www.quackwatch.org.

12 Greene CS. Where Does the Holistic End and the Quackery Begin? The Journal of the American Dental Association $1981 ; 102(1): 25-7$.

13 Scully C. Medical problems in dentistry: Elsevier Health Sciences; 2010

14 Epstein JB. The mouth: a window on systemic disease. Canadian Family Physician 1980;26:953.

15 Chapple IL, Genco R. Diabetes and periodontal diseases: consensus report of the Joint EFP/ AAP Workshop on Periodontitis and Systemic Diseases. Journal of Clinical Periodontology 2013;40(s14).
16 Tonetti MS, Dyke TE. Periodontitis and atherosclerotic cardiovascula disease: consensus report of the Joint EFP/AAP Workshop on Periodontitis and Systemic Diseases. Journal of Clinical Periodontology 2013:40(s 14).

17 Sanz M, Kornman K. Periodontitis and adverse pregnancy outcomes: consensus report of the Joint EFP/ AAP Workshop on Periodontitis and Systemic Diseases. Journal of Clinical Periodontology. 2013;40(s14).

18 Hayashi MW, N. Time to put the mouth back in the body. BM Opinion [serial on the Internet]. 2017; (January 10, 2017): Available at: http://blogs.bmj. $\mathrm{com} / \mathrm{bmi} / 2017 / 01 / 10 /$ time-toput-the-mouth-back-in-the-body. 
considered to be closely aligned to the work of Brown et al ${ }^{37}$ who had previously described patient-centred care (PCC) in terms of "understanding the whole person". This core category highlights the importance of listening and interpreting visual cues (communication), and understanding the needs of the whole patient (holistic care).

A utilitarian model of PCC has recently been proposed by Mills et al ${ }^{38}$ which focuses on the process of care delivery based on a series of qualitative patient interviews. Face validity of the model was subsequently tested with a group of general dental practitioners, which led to further refinement and identification of four key factors which were considered important in the delivery of PCC: 39

- Connection.

- Caring attitude.

- Communication.

- Control.

Holistic care and PCC are inextricably linked, and it is suggested that the four relational aspects of care identified in PCC are relevant considerations when undertaking a holistic assessment.

\section{Connection}

Establishing a connection and building rapport are key steps in collecting detailed patient information which are relevant to the patient assessment.
Trust is an important factor in a patient relationship, and as a consequence patients place considerable value on familiarity. ${ }^{40}$ Familiarity or pre-existing relationship can also greatly facilitate effective communication and is likely to provide better insight into the patient's own views, attitudes and circumstances.

Moulton refers to the "golden minutes" at the start of a consultation and explains that the first two or three minutes are crucial in obtaining important information and "building the therapeutic relationship." Simple gestures and courtesies, such as a warm greeting, introduction and a handshake are viewed as highly important by patients, but can often be overlooked by a busy healthcare professional. These initial few minutes can set the tone for the consultation, and indeed for the future dentist-patient relationship.

\section{Caring attitude}

Patients find it difficult to make an accurate judgement of the technical ability of a dentist, and instead make assumptions based on the relational skills of the practitioner. The attitude of the dental care professional can therefore have a significant impact on the perception of the patient in terms of respect, professionalism, competency and trustworthiness. These factors can have a profound influence on the willingness of the patient to engage and share information about their dental, social or medical history. Attitudinal issues can also lead to patient dissatisfaction, and ultimately complaint, if the situation is not handled appropriately. ${ }^{41}$

The importance of developing consultation skills has already been highlighted, as has the relevance of the attitudinal approach of the clinician in undertaking a holistic assessment. A non-judgemental approach has previously been identified by Loignon et $\mathrm{al}^{42}$ as a key factor in establishing rapport and breaking down barriers. Patients often present with a wide range of views, opinions and attitudes towards healthcare, and they may also be dealing with very different social challenges in comparison to those of the clinician. It is important that members of the dental team understand and acknowledge this, and develop the ability to see the world through the patient's eyes. ${ }^{43}$

\section{Communication}

Communication has been identified as a key dimension of PCC in dentistry ${ }^{38,44}$ and is clearly important in collecting and collating information, building a connection, demonstrating a caring attitude and facilitating informed decision making. ${ }^{39}$ The communication skills of "listening, questioning and explaining" are acknowledged within the SDCEP guidance as being "central to any 'dental
19 Ikebe K, Hazeyama T, Enoki K, Murai S, Okada T, Kagawa R et al. Comparison of GOHAl and OHIP 14 measures in relation to objective values of oral function in elderly Japanese. Community Dentistry And Oral Epidemiology 2012;40(5):406-14

20 Chapple IL. Time to take periodontitis seriously. BM 2014;348: 2645 .

21 Nakano K, Hokamura K, Taniguch N, Wada K, Kudo C, Nomura R et al. The collagen-binding protein of Streptococcus mutans is involved in haemorrhagic stroke. Nature Communications 2011 :2:485.

22 Ali K, Tredwin C, Kay E, Slade A Stakeholders' Perceptions About a Newly Established Dental School with a Problem-Based, Student-Led,
Patient-Centered Curriculum: A Qualitative Study. Journal of Denta Education 2016:80(3):291-300.

23 Newsome P, Smales R, Yip K. Ora diagnosis and treatment planning: part 1. Introduction. British Dental Journal 2012;213(1): 15-9.

24 NHS England. NHS Five Year Forward View, 2014. London: HMSO; 2014.

25 Department of Health. Dental contract reform: Prototypes,

Overview document. In: Legislation and Policy Unit. DaES, editor. London: HMSO; 2015.

26 Department of Health. Dental Contract Reform Pilots: Notes to support Care Pathway Approach. In: England N, editor. London: HMSO; 2013

27 Department of Health. NHS dental contract pilots - Learning after first two years of piloting. London: NHS England; 2014.

28 Overgaard Nielsen H. Dental contract reform: an update on prototypes. BDA Connect [serial on the Internet]. 2016: Available at: https://bdaconnect.bda.org/ dental-contract-reform-an-updateon-prototypes/.

29 Woodington J. Challenges facing NHS dental contract reforms: Pilot exit. British Dental Journal 2015;218(12):695-7.

30 Mills I, Batchelor P. Quality indicators: the rationale behind their use in NHS dentistry. British Dental Journal $2011 ; 211(1): 11-5$

31 Faculty of General Dental Practice (UK). Clinical Examination and Record Keeping; Good Practice Guidelines.
London: FGDP(UK); 2016

32 Scottish Dental Clinical Effectiveness Programme (SDCEP). Oral Health Assessment and Review. Dundee: Scottish Dental Clinical Effectiveness Programme; 2011

33 University of Bristol Medical School. Teachers' and Students' Handbook for Consultation Skills Teaching. Bristol: Centre for Academic Primary Care; 2014. Available at: www.bristol. ac.uk/media-library/sites/ primaryhealthcare/migrated/ documents/conshandbook.pdf.

34 Moulton L. The naked consultation: A practical guide to primary care consultation skills. London: Radcliffe Publishing; 2007.

35 General Dental Council. Preparing for practice - dental team learning 
team-patient' interaction." 32 The guidance also highlights the need to adapt and adjust communication style and methods to suit the patient and this has previously been reported as a key feature of PCC in dentistry. ${ }^{38}$

It is widely recognised that communication is not confined to the spoken word, and non-verbal communication is an important aspect of connecting, building rapport, information gathering, and displaying empathy and understanding. ${ }^{45}$ It is also important to acknowledge that communication is bidirectional, and an ability to demonstrate active listening is a critical skill which needs to be valued and developed. ${ }^{46}$ Active listening is a process in which the clinician listens attentively and "at the same time attempts to discern, interpret and summarise what the speaker is saying. " 47 In practical terms, active listening allows information to be gathered more accurately, but just as important it provides a strong indication of empathy and understanding which the patient is likely to notice. ${ }^{47}$

\section{Control}

Control, choice and empowerment are key aspects of PCC and are considered particularly important in relation to informed decision making. In terms of holistic assessment, control is likely to be most relevant with regard to power balance within the consultation. ${ }^{48}$
Increased access to medical knowledge, enhanced patent expectations, and a change in attitude towards professional authoritarianism has led to a significant shift in the power balance within medical or dental consultations. Patients are increasingly willing, and able, to take an active role.

There is a growing realisation that health outcomes, patient satisfaction and professional fulfilment benefit from a partnership approach to healthcare. ${ }^{48}$ The NHS recognises the merits of patient participation and is keen to promote the benefits of patient autonomy, personal responsibility and self-care. This is highly relevant within the consultation process, where patients should be encouraged to share their views, express opinion and take ownership of decisions about their health. Not all patients wish to embrace this approach, but everyone should at least be given the opportunity.

One of the main barriers within NHS dentistry is the time available for consultation, examination or recall. The 2006 dental contract is widely acknowledged to have been an abject failure ${ }^{49.51}$ and the introduction of the 'unit of dental activity' (UDA) has done little to slow the 'dental treadmill' as originally suggested under Options for Change. ${ }^{52}$ There is some evidence within primary care to suggest that increased efficiency can be achieved if consultations are done more effectively. ${ }^{34,48}$ The danger with this constant drive for efficiency is undoubtedly the impact this can have on maintaining the quality of care provided. It will be interesting to read the next evaluation of the contract reform prototypes, due to be published later this year, to see whether the access/quality/cost triangle in NHS dentistry has finally been solved.

\section{Summary}

As dental professionals, we have a responsibility to provide holistic care for our patients. The benefits are clear in terms of improved health outcomes, patient satisfaction and professional fulfilment. In order to achieve this successfully, we need to ensure that we have the knowledge, the skills, the desire and the time to undertake a holistic assessment.

Holistic assessment is not just about the relationship between oral disease and systemic health. It is about caring for the overall wellbeing of our patients by providing information, advice and the appropriate support. Understanding our patients' needs is key, but we can only achieve this by connecting, caring and communicating effectively. If we can achieve that, we have a much better chance of implementing a successful preventative programme with patients taking control and responsibility for their own oral health. outcomes for registration. London: GDC; 2012.

36 Kulich KR, Berggren U, Hallberg LR. A qualitative analysis of patientcentered dentistry in consultations with dental phobic patients. J Health Commun 2003;8(2): 171-87.

37 Brown J, Stewart $M$, McCracken E McWhinney IR, Levenstein J. The patient-centred clinical method. 2. Definition and application. Family Practice 1986:3(2):75-9.

38 Mills I, Frost J, Kay E, Moles D. Person-centred care in dentistry-the patients' perspective. British Dental Journal. 2015;218(7):407-13.

39 Mills IJ. The Delivery of Person Centred Care in General Dental Practice [PhD Doctoral Thesis]. Plymouth: University of Plymouth; 2017.
40 Baker R, Boulton M, Windridge K, Tarrant C, Bankart J, Freeman GK. Interpersonal continuity of care: a cross-sectional survey of primary care patients' preferences and their experiences. Br J Gen Pract. 2007;57(537):283-90

41 D'Cruz L. The successful management of complaints-turning threats into opportunities. Dental Update. 2008;35(3): 182.

42 Loignon C, Allison P, Landry A, Richard L, Brodeur JM, Bedos $C$. Providing humanistic care: dentists' experiences in deprived areas. Journal of Dental Research. 2010;89(9):991-5.

43 Gerteis M, Edgeman-Levitan S, Daley J, Delbanco TL, editors. Through the Patient's Eyes.
San Francisco: John Wiley \& Sons; 1993.

44 Scambler S, Gupta A Asimakopoulou K. Patient centred care-what is it and how is it practised in the dental surgery? Health Expectations; 2014

45 Kay EJ, Tinsley S. Communication and the dental team: Stephen Hancocks; 2004.

46 Simpson $M$, Buckman $R$, Stewart $M$, Maguire $P$, Lipkin M, Novack D et al. Doctor-patient communication: the Toronto consensus statement. BM: British Medical Journal. 1991;303(6814):1385

47 Newton JT. Matching Perception with Reality: How Patients Develop Perceptions of Treatment. Dental Journal 2015;48:53.

48 Tate P. The doctor's communication handbook: London: Radcliffe Publishing; 2010.

49 Dental contract driving dentists from nhs, select committee told. British Dental Journal 2008;204(5):230.

50 New contract failing to improve dental services say MPs, as health committee urges review of UDAs. British Dental Journal 2008;205(1):7.

51 Department of Health. NHS dental services in England An independent review led by Professor Jimmy Steele. In: Health Do, editor. London: The Stationery Office; 2009.

52 Department of Health. NHS dentistry: options for change. London: Department of Health; 2002. 


\section{Enamelon ${ }^{\circ}$}

Everyday Relief. Everyday Protection.

\section{Dispense with Confidence! $!^{1,2,3}$}

Enamelon ${ }^{\circledast}$ Preventive Treatment Gel's exclusive formulation combines stabilized stannous fluoride optimized with Amorphous Calcium Phosphate (ACP) technology to help treat and prevent sensitivity, promote remineralization, inhibit demineralization and soothe and moisturize dry mouth tissues.

\section{$8+4 !^{*}$}

Buy 8 tubes of Enamelon, Get 4 tubes FREE!*

\section{SPECIAL!*}

\section{SPECIALI*}

Premierø Dental Products Company • intlinfo@premusa.com • 610-239-6000 • www.premusa.com

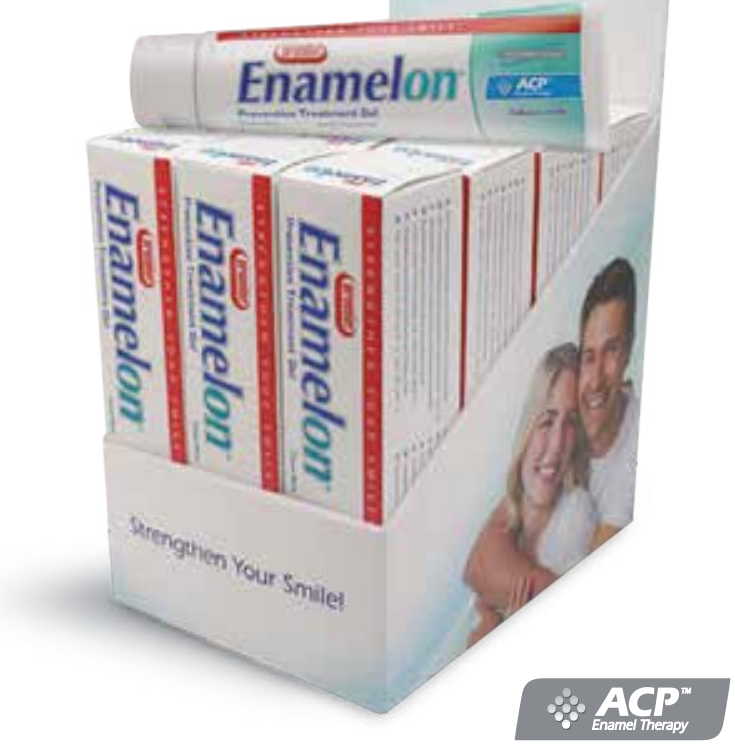

Available through: CTS Dental Supplies • Dental Sky • Henry Schein • Kent Express • Wright Cottrell

*Contact your authorized dealer for details. / 1. Comisi DDS.,MAGD, John C., The Catapult Group presents its review on this unique, protective, remineralizing and moisture-enhancing preventive treatment gel, Dental Product Report, 2015, October; Issue 10 Vol. $9: 68$-69 / 2. Schemehorn BR, DiMarino JC, Movahed N. Comparison of the enamel solubility reduction from various prescription and OTC fluoride toothpastes and gels. J Clin Dent 2014;25:61-4. / 3. Schemehorn BR, DiMarino JC, Movahed N. Comparison of the incipient lesion enamel fluoride uptake from various prescription and OTC fluoride toothpastes and gels. J Clin Dent 2014;25:57-60.

/ Enamelon ${ }^{\circledast}$ United States Patent Numbers: US 5,993,784, US 5,711,936, US 5,651,959 and other patents pending. / Made in U.S.A. / Ultramulsion ${ }^{\circledast}$ is a registered trademark of WhiteHill Oral Technologies, Inc.

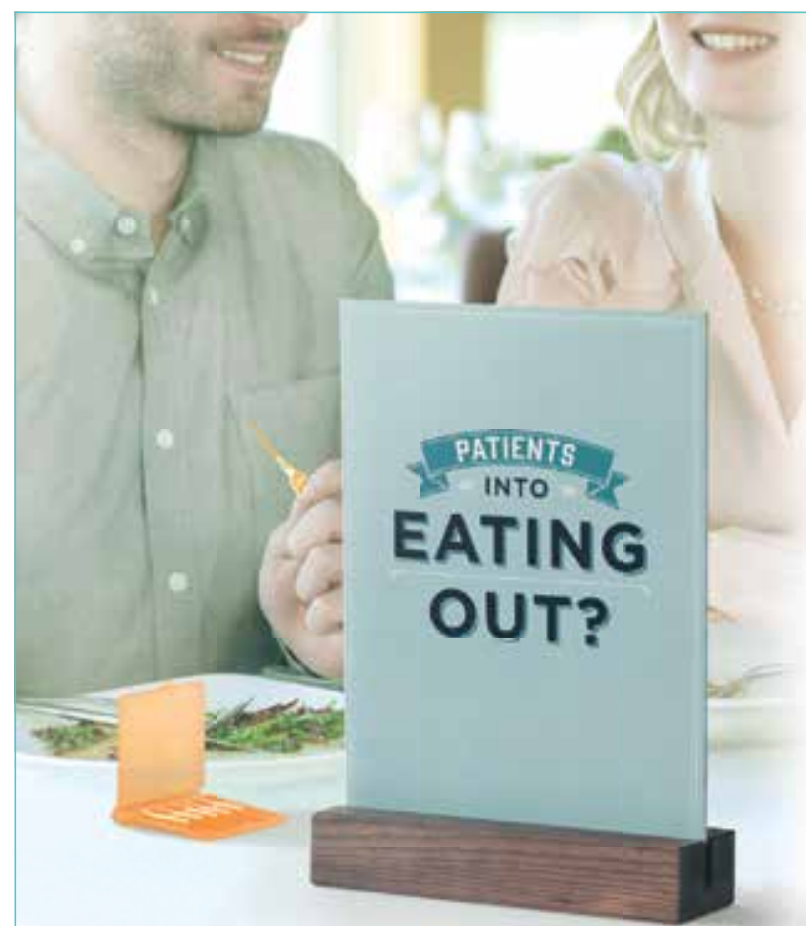

So is TePe EasyPick.
TePe EasyPick promotes a healthy new on-the-go dental habit, making it easy for patients to remove trapped food when they eat out.

- Comes in two tapered sizes for easy cleaning of all interdental spaces

- Handy travel case format encourages frequent on-the-go use

- Increases the likelihood of habit formation*

*Frequency of use increases the likelihood of habit formation (Lally et al 2010).

\section{Order from your wholesaler today.}

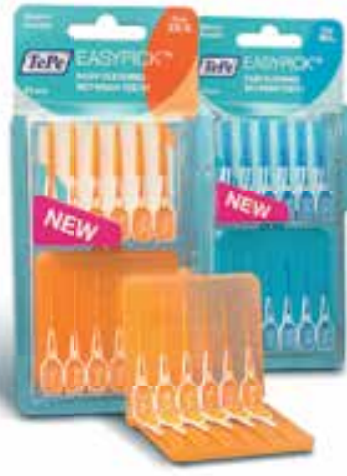

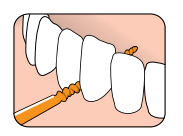

Easy to insert between the teeth.

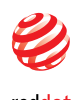

reddot award 2016 winner

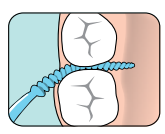

Flexible for easy reach between the back teeth. www.tepe-easypick.com 